\title{
Gambaran Pertumbuhan Anak dengan Hipotiroid Kongenital Pasca- Terapi Levotiroksin di RSUP Dr. Hasan Sadikin pada Tahun 2014 sampai dengan 2018
}

\author{
Noviola Ruth Adisty, ${ }^{1}$ Faisal, ${ }^{2}$ Basuki Hidayat ${ }^{3}$ \\ ${ }^{1}$ Prodi Pendidikan Dokter, ${ }^{2}$ Prodi/Departemen Ilmu Kesehatan Anak, ${ }^{3}$ Prodi/Departemen Ilmu Kedokteran Nuklir dan Pencitraan
} Molekuler Fakultas Kedokteran Universitas Padjadjaran/RSUP Dr. Hasan Sadikin, Bandung

\begin{abstract}
Pendahuluan. Hipotiroid kongenital merupakan penyebab gangguan tumbuh kembang anak yang dapat dicegah dengan terapi levotiroksin dini. Akan tetapi di Indonesia, diagnosis dini berdasarkan skrining hipotiroid kongenital cakupannya rendah sehingga banyak kasus mengalami gangguan pertumbuhan akibat keterlambatan terapi.

Tujuan. Mengetahui gambaran pertumbuhan anak dengan hipotiroid kongenital pasca-terapi levotiroksin.

Metode. Penelitian retrospektif potong lintang menggunakan data rekam medis pasien anak dengan hipotiroid kongenital selama kurun waktu 2014-2018 di Poli Anak RSUP Dr. Hasan Sadikin. Pertumbuhan dipantau berdasarkan laju pertumbuhan linear dan indeks antropometri kurva pertumbuhan WHO 2005.

Hasil. Sejumlah 51 pasien memenuhi kriteria, mayoritas subjek didiagnosis hipotiroid kongenital pada usia 0-12 bulan (78,4\%), berjenis kelamin laki-laki (60,8\%), dan memiliki komorbiditas (66,7\%). Rerata laju pertumbuhan linear berdasarkan kelompok usia 0-12 bulan $(\mathrm{n}=40), 1-2$ tahun $(\mathrm{n}=3), 2-5$ tahun $(\mathrm{n}=1)$ dan $>5$ tahun $(\mathrm{n}=7)$, berturut-turut $21,77,3 \mathrm{~cm} /$ tahun, 10,23,8 cm/tahun, 8,6 $\mathrm{cm} /$ tahun, dan 13,55,2 cm/tahun. Komorbiditas tidak ditemukan pada subjek usia 2-5 dan $>5$ tahun. Pasca-terapi, 9 subjek dengan perawakan sangat pendek/pendek pre-terapi menjadi berperawakan normal, 8/9 subjek usia 0-12 bulan dan sisanya $>5$ tahun, serta semuanya tidak memiliki komorbiditas.

Kesimpulan. Pertumbuhan anak mengalami perbaikan pasca-terapi levotiroksin berdasarkan laju pertumbuhan linear dan indeks antropometri terutama pada anak yang diterapi dini dan tanpa komorbiditas. Sari Pediatri 2020;22(2):98-103
\end{abstract}

Kata kunci: hipotiroid kongenital, pertumbuhan, levotiroksin

\section{Growth of Children with Congenital Hypothyroidism Post-Levothyroxine Theraphy at Hasan Sadikin General Hospital on 2014 until 2018}

Noviola Ruth Adisty, ${ }^{1}$ Faisal, ${ }^{2}$ Basuki Hidayat ${ }^{3}$

Background. Congenital hypothyroidism causes growth disorders in children which could be prevented by early levothyroxine therapy. However, in Indonesia, early diagnosis by newborn screening hasn't completely covered all children, so most cases would likely experience growth disturbance due to delayed therapy.

Objective. To determine the growth of children with congenital hypothyroidism post-levothyroxine therapy.

Methods. A cross-sectional retrospective study using data on medical records of patients with congenital hypothyroidism $2014-2018$ at Department of Pediatrics Hasan Sadikin General Hospital. Growth is evaluated by linear growth rate and anthropometric indexes using 2005 WHO Growth Chart.

Results. 51 patients met the criteria, most subjects were diagnosed at 0-12 months old (78.4\%), were male(60.8\%), and had comorbidities (66.7\%). The average linear growth rate based on age of $0-12$ months old $(\mathrm{n}=40), 1-2$ years old( $\mathrm{n}=3)$, 2-5 years old $(\mathrm{n}=1)$ and $>5$ years old $(\mathrm{n}=7)$ subjects were $21.7 \pm 7.3 \mathrm{~cm} /$ year, $10.2 \pm 3.8 \mathrm{~cm} /$ year, $8.6 \mathrm{~cm} /$ year, and $13.5 \pm 5.2 \mathrm{~cm} /$ year, respectively. Comorbidity wasn't found in children aged 2-5 and $>5$ years old. After therapy, 9 subjects with very short/short stature pre-therapy became normal, 8/9 subjects aged 0-12 months old, and 1/9 aged $>5$ years old, they had no comorbidities.

Conclusion. Growth improved after therapy based on linear growth rate and anthropometric index, especially in children treated early and without comorbidities. Sari Pediatri 2020;22(2):98-103

Keywords: congenital hypothyroidism, growth, levothyroxine

Alamat korespondensi: Faisal. Departemen Ilmu Kesehatan Anak Fakultas Kedokteran Universitas Padjadjaran/Rumah Sakit Umum Pusat Dr. Hasan Sadikin, Jl. Pasteur no. 38, Bandung 40161 Email: faisal@unpad.ac.id 
$\mathrm{H}$ ipotiroid Kongenital (HK) merupakan kondisi klinis yang muncul akibat kekurangan hormon tiroid yang bersifat bawaan. ${ }^{1,2}$ Hormon tiroid berperan dalam proses tumbuh kembang anak sehingga kondisi hipotiroid menyebabkan perlambatan proses tumbuh kembang. ${ }^{3,4}$ Kebutuhan hormon tiroid pada masa janin bersumber dari hormon tiroid ibu. Hal ini yang menyebabkan bayi dengan HK pada umumnya memiliki tumbuh kembang normal sesuai usia kehamilan dan tidak menunjukkan gejala klinis sesaat setelah dilahirkan. ${ }^{1}$ Oleh karena itu, deteksi dini bayi dengan $\mathrm{HK}$ sebelum munculnya gejala klinis menjadi penting agar terapi dapat segera diberikan sehingga risiko kegagalan pertumbuhan dapat dihindari/diminimalisasi. Deteksi dini HK adalah melalui pemeriksaan kadar thyroid-stimulating hormone (TSH) yang dilakukan pada bayi berusia 3 hingga 5 hari; dalam program Skrining Hipotiroid Kongenital (SHK). ${ }^{5}$

Di Indonesia, berdasarkan hasil skrining yang dilakukan sejak tahun 2000 hingga 2013, angka kejadian kasus HK adalah 1:2736 kelahiran. ${ }^{5}$ Akan tetapi, pada tahun 2014, dari 4,7 juta kelahiran di Indonesia, kurang dari $2 \%$ bayi baru lahir yang melaksanakan pemeriksaan SHK. Hal ini menyebabkan sebagian besar anak dengan HK di Indonesia terlambat didiagnosis dan diterapi. ${ }^{6}$ Anak dengan HK yang terlambat diterapi akan mengalami perlambatan pertumbuhan. ${ }^{7}$

Perlambatan pertumbuhan dapat diatasi dengan pemberian terapi yang tepat dan adekuat. Terapi standar untuk pasien HK adalah substitusi hormon tiroid. Sediaan hormon tiroid yang biasa digunakan untuk terapi tersebut adalah hormon tiroksin, yakni levotirok$\sin \left(\mathrm{L}-\mathrm{T}_{4}\right){ }^{2,5,8-10}$ Pemberian levotiroksin dapat memenuhi kebutuhan hormon tiroid anak sehingga mampu mengompensasi keterlambatan proses pertumbuhan pada anak dengan HK. Keberhasilan terapi dapat dipantau melalui pemantauan pertumbuhan melalui laju pertumbuhan linear dan indeks antropometri menggunakan kurva pertumbuhan World Health Organization (WHO) 2005.

Pada saat ini, di Indonesia, laporan yang ada mengenai gambaran pertumbuhan pasien HK pascaterapi levotiroksin hanya melibatkan jumlah subjek yang tidak banyak. ${ }^{11-13}$ Kondisi ini mendorong untuk dilakukannya penelitian mengenai gambaran pertumbuhan anak dengan HK pasca-terapi levo- tiroksin dengan jumlah subjek yang lebih banyak dengan menggunakan laju pertumbuhan linear dan indeks antropometri sebagai acuan.

\section{Metode}

Penelitian deskriptif dengan rancangan potong lintang (cross-sectional) ini dilakukan di Poli Anak Departemen Ilmu Kesehatan Anak RSUP Dr. Hasan Sadikin (RSHS), setelah mendapatkan persetujuan kelayakan dari komite etik penelitian kesehatan Fakultas Kedokteran Universitas Padjadjaran, serta izin dari Bagian Pendidikan dan Penelitian RSUP Dr. Hasan Sadikin. Data dikumpulkan dari rekam medik semua pasien anak yang didiagnosis $\mathrm{HK}$ pada periode 1 Januari 2014 sampai dengan 31 Desember 2018 di Poli Anak RSHS. Kriteria inklusi adalah pasien HK yang didiagnosis berdasarkan gambaran klinis dan kadar TSH $>5 \mathrm{uIU} / \mathrm{mL}$, sedang dalam terapi levotiroksin, serta melaksanakan kontrol untuk pemantauan keberhasilan terapi minimal sebanyak 4 kali. Kriteria eksklusi berupa pasien HK dengan penyakit infeksi kronis (seperti tuberkulosis, helminthiasis, dan lainnya) dan keganasan (seperti leukemia, osteochondroma, dan lainnya) yang dapat memengaruhi pertumbuhan.

Variabel penelitian ini adalah usia saat diagnosis, jenis kelamin, komorbiditas, kelompok HK berdasarkan etiologi, manifestasi klinis, laju pertumbuhan linear, dan indeks antropometri. Laju pertumbuhan linear dipantau menggunakan nilai referensi dari American Academy of Family Physicians 2015 (AAFP 2015). Indeks antropometri yang digunakan untuk anak usia $>2$ tahun adalah tinggi badan/usia $(\mathrm{TB} / \mathrm{U})$ dan berat badan/tinggi badan (BB/TB), sedangkan untuk anak usia 0-2 tahun adalah panjang badan/usia $(\mathrm{PB} / \mathrm{U})$ dan berat badan/panjang badan $(\mathrm{BB} / \mathrm{PB})$, serta indeks masa tubuh/usia (IMT/U) untuk semua subjek.

Adanya komorbiditas diambil dari diagnosis selain HK yang tertera pada rekam medis. Data manifestasi klinis dicatat sesuai dengan data yang tertera pada rekam medis. Pada pasien HK yang melaksanakan pemeriksaan sidik kelenjar tiroid, dilakukan pengelompokan HK berdasarkan etiologi. Dikelompokkan agenesis tiroid apabila tidak ditemukannya adanya penangkapan radiofarmaka di lapang tiroid, maupun bagian leher lainnya selain penangkapan yang fisiologis. Dikelompokkan hipoplasia tiroid apabila didapatkan adanya sedikit penangkapan radiofarmaka di lapang 
tiroid. Dikelompokkan tiroid ektopik apabila didapatkan adanya penangkapan radiofarmaka di luar lapang tiroid selain penangkapan fisiologis pada leher. Dikelompokkan dishormonogenesis apabila didapatkan citra morfologi fungsional normal dari kelenjar tiroid yang disertai oleh pemeriksaan kadar TSH yang menunjukkan adanya $\mathrm{HK}^{2}$

Pemantauan pertumbuhan mulai dilakukan saat terapi pertama kali diberikan sampai kurang lebih 6 bulan pasca-terapi berdasarkan catatan tinggi badan dan berat badan anak yang tertera di rekam medis. Pertumbuhan dinilai menggunakan laju pertumbuhan linear berdasarkan nilai referensi AAFP 2015, serta indeks antropometri menggunakan kurva pertumbuhan WHO 2005. ${ }^{14}$ Data berupa jumlah, persentase, rata-rata, serta nilai tengah diolah dengan menggunakan Microsoft Excel 2013 dan disajikan dalam bentuk Tabel.

\section{Hasil}

Berdasarkan daftar pasien anak yang tertera di buku register Poli Anak RSHS, jumlah pasien HK yang

Tabel 1 Karakteristik umum pasien

\begin{tabular}{lcc}
\hline & \multicolumn{2}{c}{ Hipotiroid kongenital } \\
\cline { 2 - 3 } Karakteristik & $\mathrm{n}$ & $\%$ \\
\hline Usia diagnosis & 40 & 78,4 \\
$0-12$ bulan & 17 & 42,5 \\
0 -3 bulan & 23 & 57,5 \\
3-12 bulan & 3 & 5,9 \\
1-2 tahun & 1 & 2 \\
2-5 tahun & 7 & 13,7 \\
$>5$ tahun & & \\
Jenis kelamin & 20 & 39,2 \\
Perempuan & 31 & 60,8 \\
Laki-laki & & \\
Komorbiditas & 17 & 33,3 \\
Tanpa komorbid & 34 & 66,7 \\
Dengan komorbid & & \\
Etiologi HK & 19 & 37,2 \\
Tidak diketahui & 32 & 62,8 \\
Diketahui & 12 & 37,5 \\
Agenesis & 11 & 34,4 \\
Dishormogenesis & 7 & 21,8 \\
Hipoplasia & 2 & 6,3 \\
Ektopik & & \\
\hline
\end{tabular}

didiagnosis pada periode penelitian adalah 82 anak. Namun, 12 anak memiliki data rekam medis yang tidak tersimpan di instalasi rekam medis. Dari 70 data yang terkumpul, 19 pasien dieksklusi karena riwayat pemantauan tumbuh kembang yang tidak lengkap dan 2 pasien dieksklusi karena memiliki penyakit infeksi kronis sehingga jumlah subjek yang digunakan 51 anak.

Tabel 1 menunjukkan karakteristik umum pasien HK di Poli Anak RSHS periode Januari 2014 sampai dengan Desember 2018. Data menunjukkan bahwa sebagian besar pasien HK didiagnosis pada usia 0-12 bulan $(78,4 \%)$, berjenis kelamin laki-laki $(60,8 \%)$, dan memiliki komorbiditas (66,7\%). Komorbid dengan jumlah terbanyak adalah sindrom Down sebanyak $41,2 \%$, kemudian diikuti oleh penyakit jantung bawaan 31,4\%. Dari 34 pasien HK yang memiliki komorbiditas, 31 pasien berusia 0-12 dan 3 pasien berusia 1-2 tahun

Tabel 2 menunjukkan manifestasi klinis pasien HK. Data menunjukkan bahwa pasien dapat memiliki kombinasi beberapa manifestasi klinis sekaligus dan yang paling banyak ditemukan adalah wajah tipikal HK sebanyak $86,3 \%$.

Tabel 3 menunjukkan hasil pemeriksaan laju pertumbuhan linear pasien HK. Pada penelitian ini dilaporkan bahwa laju pertumbuhan linear paling cepat terjadi pada pasien anak usia $0-12$ bulan, yaitu dengan rata-rata $21,7 \pm 7,3 \mathrm{~cm} /$ tahun dan nilai tengah $21,4 \mathrm{~cm} /$ tahun. Hanya didapatkan satu data pada kelompok anak usia 2-5 tahun dengan laju pertumbuhan linear $8,7 \mathrm{~cm} /$ tahun. Sebanyak $53 \%$ pasien memiliki laju pertumbuhan nomal dan di

Tabel 2. Manifestasi klinis pasien

\begin{tabular}{lcc}
\hline & \multicolumn{2}{c}{ Hipotiroid kongenital } \\
\cline { 2 - 3 } Karakteristik & $\mathrm{n}$ & $\%$ \\
\hline Wajah tipikal & 44 & 86,3 \\
Makroglosi & 29 & 56,9 \\
Penurunan aktivitas & 24 & 47,1 \\
Konstipasi & 23 & 45,1 \\
Kulit kering & 16 & 31,4 \\
Skin mottling & 15 & 29,4 \\
Hidung pesek & 6 & 11,8 \\
perut buncit & 4 & 7,8 \\
edema palpebral & 4 & 7,8 \\
edema tungkai & 2 & 3,9 \\
ikterus & 2 & 3,9 \\
\hline
\end{tabular}


Tabel 3. Hasil pemeriksaan laju pertumbuhan linear

\begin{tabular}{lcc}
\hline Kelompok usia & $\begin{array}{c}\text { Laju pertumbuhan } \\
\text { linear (cm/tahun) }\end{array}$ & $\begin{array}{c}\text { Nilai } \\
\text { referensi }(\mathrm{cm} / \\
\text { tahun })\end{array}$ \\
\hline Usia 0-12 bulan & $21,7 \pm 7,3$ & $23-27$ \\
\hline Rata-rata & 21,4 & \\
Nilai tengah & & \\
Usia 1-2 tahun & $10,2 \pm 3,8$ & $10-12$ \\
Rata-rata & 9,2 & \\
Nilai tengah & $8-8$ \\
Usia 2-5 tahun & 8,7 & \\
Usia $>$ tahun & & $5-6$ \\
Rata-rata & $13,9 \pm 5,2$ & \\
Nilai tengah & 14,5 & \\
\hline
\end{tabular}

atas normal, sedangkan sisanya di bawah normal. Pasien-pasien yang memiliki laju pertumbuhan linear di bawah normal terdiri dari pasien yang didiagnosis pada usia 0-12 bulan (22 dari 40 pasien) dan 1-2 tahun ( 2 dari 3 pasien).

Tabel 4 menunjukkan hasil pemeriksaan indikator pertumbuhan $\mathrm{TB} / \mathrm{U}$ atau $\mathrm{PB} / \mathrm{U}$. Data penelitian menunjukkan bahwa 9 pasien $\mathrm{HK}$ mengalami perubahan dari berperawakan sangat pendek/pendek menjadi berperawakan normal setelah diterapi. Dari 9 pasien tersebut, 8 pasien didiagnosis pada usia $0-12$ bulan dan 1 pasien didiagnosis pada usia $>5$ tahun.

Tabel 5 menunjukkan hasil pemeriksaan status gizi berdasarkan indikator pertumbuhan $\mathrm{BB} / \mathrm{TB}$ dan IMT/U. Data hasil penelitian menunjukkan bahwa terdapat kenaikan status gizi $25 \%$ berdasarkan indikator $\mathrm{BB} / \mathrm{TB}$ dan $\mathrm{BB} / \mathrm{TB}$, serta $31 \%$ berdasarkan IMT/U setelah terapi diberikan.
Tabel 5. Hasil pengukuran status gizi

\begin{tabular}{lcccc}
\hline \multirow{2}{*}{$\begin{array}{l}\text { Hasil pengukuran status gizi } \\
\text { (z score) }\end{array}$} & \multicolumn{5}{c}{ Hipotiroid kongenital } \\
\cline { 2 - 6 } & $<5$ tahun & $>5$ & tahun \\
\cline { 2 - 5 } & $\mathrm{A}$ & $\mathrm{B}$ & $\mathrm{A}$ & $\mathrm{B}$ \\
\hline Berdasarkan BB/TB atau BB/PB & & & & \\
Sangat kurus & 17 & 15 & - & - \\
Kurus & 8 & 4 & - & - \\
Normal & 17 & 22 & - & - \\
Beresiko gizi lebih & 2 & 2 & - & - \\
Gizi lebih & 0 & 1 & - & - \\
Obesitas & 0 & 0 & - & - \\
\hline Total & 44 & 44 & - & - \\
\hline & & & & \\
\hline Berdasarkan IMT/U & & & & \\
\hline Sangat kurus & 21 & 14 & 0 & 0 \\
Kurus & 6 & 3 & 0 & 0 \\
Normal & 16 & 23 & 2 & 6 \\
Berisiko gizi lebih & 1 & 3 & - & - \\
Gizi lebih & 0 & 1 & 3 & 0 \\
Obesitas & 0 & 0 & 2 & 1 \\
\hline TOTAL & 44 & 44 & 7 & 7 \\
\hline
\end{tabular}

*Keterangan:

$\mathrm{A}=$ sebelum terapi; $\mathrm{B}=$ setelah terapi

\section{Pembahasan}

Data penelitian ini menunjukkan bahwa sebagian besar pasien $(78,4 \%)$ didiagnosis pada usia kurang dari 1 tahun, tetapi hanya $33 \%$ pasien didiagnosis sebelum usia 3 bulan. Padahal pemberian terapi hormon yang adekuat sebelum usia 3 bulan dapat mengurangi keterlambatan tumbuh kembang dengan maksimal. ${ }^{5}$ Sebagian besar pasien HK pada penelitian ini disertai dengan komorbiditas $(66,7 \%)$. Banyaknya jumlah pasien dengan komorbiditas disebabkan oleh data yang diambil berasal dari RSHS yang merupakan rumah sakit Pemberi Pelayanan Kesehatan (PPK) III

Tabel 4. Hasil pemeriksaan TB/U atau PB/U pasien $\mathrm{H} K$

\begin{tabular}{|c|c|c|c|c|c|c|c|c|c|c|}
\hline \multirow[t]{3}{*}{ Hasil pengukuran $\mathrm{TB} / \mathrm{U}$ atau $\mathrm{PB} / \mathrm{U}$} & \multicolumn{10}{|c|}{ Hipotiroid kongenital $(n=51)$} \\
\hline & \multicolumn{2}{|c|}{$0-12$ bulan } & \multicolumn{2}{|c|}{$1-2$ tahun } & \multicolumn{2}{|c|}{$2-5$ tahun } & \multicolumn{2}{|c|}{$>5$ tahun } & \multicolumn{2}{|c|}{$\mathrm{N}$} \\
\hline & A & B & A & $\mathrm{B}$ & A & $\mathrm{B}$ & A & $\mathrm{B}$ & A & B \\
\hline Sangat pendek $(<-3)$ & 19 & 13 & 1 & 1 & 1 & 1 & 6 & 6 & 27 & 21 \\
\hline Pendek (-3 s/d -2) & 9 & 7 & 1 & 1 & 0 & 0 & 1 & 0 & 11 & 8 \\
\hline Normal (-2 s/d 3) & 12 & 20 & 1 & 1 & 0 & 0 & 0 & 1 & 13 & 22 \\
\hline Tinggi (>3) & 0 & 0 & 0 & 0 & 0 & 0 & 0 & 0 & 0 & 0 \\
\hline Total & 40 & 40 & 3 & 3 & 1 & 1 & 7 & 7 & 51 & 51 \\
\hline
\end{tabular}

Keterangan: $\mathrm{A}=$ sebelum terapi; $\mathrm{B}=$ setelah terapi 
sehingga pasien yang ditangani memiliki komorbiditas dan komplikasi lanjutan. Persentasi etiologi HK sesuai dengan hasil persentasi global, yaitu $65,6 \%$ kasus disebabkan oleh disgenesis kelenjar tiroid (agenesis, hypoplasia, dan ektopik) dan sisanya akibat dishormonogenesis. ${ }^{2}$

Laju pertumbuhan linear yang normal atau di atas normal $53 \%$ pasien. Pasien yang gagal mencapai laju pertumbuhan linear yang normal $47 \%$, terdiri dari 22 pasien yang diagnosis pada usia $0-12$ bulan dan 2 dengan usia diagnosis 1-2 tahun. Adapun hal ini disebabkan oleh komorbiditas pada $66,7 \%$ pasien HK yang seluruhnya terjadi pada pasien dengan usia diagnosis 0 -12 bulan dan 1-2 tahun, serta didominasi oleh sindrom Down $(41,2 \%)$. Laju pertumbuhan linear anak dengan sindrom Down lebih lambat dari anak normal, terutama pada usia 6 bulan hingga 3 tahun. ${ }^{15}$ Seluruh pasien HK yang didiagnosis pada usia 2-5 dan $>5$ tahun memiliki laju pertumbuhan linear di atas normal dan tidak memiliki komorbiditas.

Dari hasil pengukuran laju pertumbuhan linear, kenaikan laju pertumbuhan linear kelompok usia 2-5 tahun dan $>5$ tahun terlihat sangat jelas jika dibandingkan dengan kelompok usia 0-12 bulan dan 1-2 tahun. Hal ini disebabkan oleh komorbiditas yang hanya dimiliki oleh pasien yang didiagnosis di usia 0-12 bulan dan 1-2 tahun. Selain itu, sebanyak 30\% pasien berusia $0-12$ bulan dan 33\% pasien berusia 1-2 tahun telah berperawakan normal sebelum terapi diberikan. Oleh karena itu, tujuan terapi berbeda dengan pasien kelompok usia 2-5 tahun dan $>5$ tahun yang seluruhnya berperawakan pendek/sangat pendek sebelum terapi diberikan. Tujuan terapi levotiroksin untuk pasien yang sejak awal telah berperawakan normal adalah mempertahankan pertumbuhan yang baik, sedangkan tujuan terapi untuk pasien yang awalnya berperawakan dibawah normal adalah memperbaiki pertumbuhan dengan mempercepat laju pertumbuhan linear.

Data penelitian menunjukkan bahwa 28,6\% kelompok usia 0-12 bulan yang sebelumnya berperawakan pendek/sangat pendek mengalami kenaikan menjadi berperawakan normal berdasarkan indeks antropometri TB/U setelah terapi diberikan. Sementara hanya 1 dari 7 pasien $(14,3 \%)$ kelompok usia $>5$ tahun yang mengalami kenaikan dari berperawakan pendek menjadi normal setelah terapi diberikan. Pasien-pasien ini tidak memiliki sindrom Down dan memiliki rata-rata laju pertumbuhan linear diatas normal. Oleh karena itu, perbaikan pertumbuhan lebih banyak dialami oleh pasien-pasien yang didiagnosis dan diterapi lebih dini.

Berdasarkan indeks antropometri BB/TB dan IMT/U, pasien HK mengalami perbaikan status gizi setelah pemberian terapi. Hal ini sesuai dengan penelitian oleh Wirawan dkk. ${ }^{12}$

Penelitian ini memiliki keterbatasan, seperti jangka waktu pengamatan pertumbuhan yang terlalu pendek sehingga pencapaian tinggi badan yang sesuai dengan target genetik beberapa pasien yang membutuhkan waktu lebih lama untuk mengejar keterlambatan tinggi badan tidak dicantumkan. Selain itu, adanya faktor perancu, yaitu komorbiditas, yang memengaruhi keberhasilan pencapaian pertumbuhan yang maksimal setelah terapi levotiroksin. Hal ini mungkin disebabkan oleh data berasal dari RSHS yang merupakan rumah sakit PPK III sehingga pasien yang datang memiliki komorbiditas. Oleh karena itu, saran untuk penelitian selanjutnya adalah data diambil dari PPK I atau PPK II dan memperpanjang waktu penelitian.

\section{Kesimpulan}

Pertumbuhan anak dengan HK mengalami perbaikan pasca-terapi levotiroksin berdasarkan pemantauan laju pertumbuhan linear dan indikator pertumbuhan. Keberhasilan terapi levotiroksin dalam memperbaiki pertumbuhan anak lebih baik pada pasien dengan usia diagnosis dini dan tanpa komorbiditas.

\section{Daftar pustaka}

1. LaFranchi SH. Hypothyroidism. Dalam: Kliegman RM, Stanton BF, Schor NF, III JWSG, Behrman RE, penyunting. Nelson Textbook of Pediatrics. Edisi ke-19. Philadelphia: Elsevier Saunders; 2011.h.1895-902.

2. Rastogi M V, LaFranchi SH. Congenital hypothyroidism. Orphanet J Rare Dis 2010;5:1-22.

3. Cooper DS, Ladenson PW. The thyroid gland. Dalam: Gardner DG, Shoback D, penyunting. Greenspan's Basic \& Clinical Endocrinology. Edisi ke-9. China: The McGraw-Hill Companies, Inc; 2011.h.163-226.

4. Hall JE. Guyton and hall textbook of medical physiology. Edisi ke-13. Elsevier. Philadelphia: Elsevier, Inc; 2016.

5. Kementrian Kesehatan Republik Indonesia. Pedoman skrining hipotiroid kongenital. Mranani F, penyunting. Jakarta: Kementerian Kesehatan RI; 2014. 
6. Therrell BL, Padilla CD, Loeber JG, Kneisser I, Saadallah A, Borrajo GJC, dkk. Current status of newborn screening worldwide: 2015. Semin Perinatol 2015;39:171-87.

7. Soliman AT, De Sanctis V, Bedair ES. Congenital hypothyroidism: effects on linear growth, catch- up growth, GH-IGF-I axis and bones. Dalam: Current topics in hypothyroidism with focus on development. InTech; 2013.h.91-107.

8. Dayal D, Prasad R. Congenital hypothyroidism: current perspectives. Res Reports Endocr Disord 2015;5:91-102.

9. Jonklaas J, Bianco AC, Bauer AJ, Burman KD, Cappola AR, Celi FS, dkk. Guidelines for the Treatment of Hypothyroidism: Prepared by the American Thyroid Association Task Force on Thyroid Hormone Replacement. Thyroid 2014;24:1670-751.

10. Grüters A, Krude H. Detection and treatment of congenital hypothyroidism. Nat Rev Endocrinol 2012;8:104-13.
11. Deliana M, Batubara JR, Tridjaja B, Pulungan AB. Hipotiroidisme kongenital di Bagian Ilmu Kesehatan Anak RS Ciptomangunkusumo Jakarta, tahun 1992-2002. Sari Pediatri 2003;5:79-84.

12. Wirawan A, Sunartini, Suryawan B, Soetjiningsih. Tumbuh kembang anak hipotiroid kongenital yang diterapi dini dengan levo-tiroksin dan dosis awal tinggi. Sari Pediatri 2013;15:69-74.

13. Maswiryati AA, Westra N. Congenital hypothyroidism: a case report. Paediatr Indones 2003;43:31-4.

14. Kementrian Kesehatan Republik Indonesia. Keputusan Menteri Kesehatan Republik Indonesia Nomor 1995/Menkes/ SK/XII/2010 tentang standar antropometri penilaian status gizi anak. Jakarta; 2011.

15. Myrelid A, Gustafsson J, Ollars B, Anneren G. Growth charts for Down's syndrome from birth to 18 years of age. Arch Dis Child 2002;87:97-103. 